\section{Age-related cataract and place of birth}

\author{
Abstract \\ Cataract patient data from 13 Australian \\ practitioners were analysed in order to \\ compare the distribution of seven principal \\ types of cataract in relation to gender, age and \\ place of birth. Relative odds ratios were \\ calculated for age-matched pairs of three \\ identifiable ethnic groups and each type of \\ cataract. The number of statistically significant \\ relative odds ratios far exceeds the expectation \\ due to chance. The results suggest a relatively \\ greater risk for cortical cataract amongst \\ younger when compared with older groups. In \\ contrast, the relative odds ratios for nuclear \\ cataract, independently of age, were \\ consistently greater than unity when \\ Australians or Northern Europeans were \\ compared with Southern Europeans. There \\ was no gender-based difference in cataract \\ type distribution.
}

Key words Ageing, Cataract, Ethnicity

Recent epidemiological studies have identified a number of risk factors for cataract. The strongest is age. However, the processes of ageing are themselves subject to a variety of influences and, accordingly, age-related cataract is probably the result of both environmental ${ }^{1.2}$ and genetic ${ }^{3}$ causes. However, little attention has been directed to those factors of regional origin. Recent studies have considered possible links between ethnicity and age-related cataract types. ${ }^{4,5}$ As it is desirable to determine the influence of environment, if any, in order to determine risk factors the outcome of which can be influenced, an examination of groups of different ethnic origin living in the same country is useful. Australia is suitable because she offers excellent ethnically heterogeneous, but coherent, patient pools. The work reported in this paper investigates three major ethnic groups in Australia and is an extension of a previous study. 5

The criterion of place of birth as an index of ethnicity may be open to argument, but there is little to suggest much mobility or mixing between the Southern and Northern European immigrants studied, who belong to the higher age-groups.
BARBARA K. PIERSCIONEK, ROBERT A. WEALE

A number of risk factors have been identified. ${ }^{1,2}$ In this study age, diabetes, trauma and steroid intake were controlled.

\section{Methods \\ Data collection}

Thirteen practitioners in Australia (11 in Victoria, 1 in Western Australia and 1 in South Australia) were invited to participate in this study. The data sought, subject to patient consent, were: age, gender, place of birth and cataract type. The last was based on a separation into the three main types, namely cortical $(C)$, nuclear $(\mathrm{N})$ and posterior subcapsular $(\mathrm{P})$ cataracts, as well as the four mixed categories $(\mathrm{CN}, \mathrm{NP}, \mathrm{PC}, \mathrm{CNP})$. All the diagnoses were based on slit-lamp examinations carried out by practitioners of at least 10 years' experience and a visual acuity of $6 / 9$ or less in the worse eye. Practitioners were asked to exclude patients with cataract due to trauma, diabetes or steroids, and stratification was used for age. The numbers in the two genders differed (Table 2a). One of the results raised the question of being confounded by age, which led to a tentative adjustment as set out in the Discussion.

The 872 patients used in this study were categorised as Australian ( $\mathrm{Au}$ ), North European (NE) or South European (SE). In fact, the number obtained was larger, but included ethnic groups that are not under consideration at present. No Aborigine was included. Twelve ophthalmological and optometric practitioners contributed to $\mathrm{Au}, 11$ to $\mathrm{NE}$, and 10 to SE. The data base includes 441 results previously reported.

Two possibly relevant factors were not controlled. The first is smoking (cf. ${ }^{6-8}$ ). The question of its relation to (nuclear) cataract is as yet unresolved," and any result linked to this study would be based merely on what the patient may (wish to) remember - which may not be reliable, because there is a groundswell of public opinion antagonistic to smokers. The second is the duration of residency which, likewise, is not easy to document without stressing, for example, older patients; though not recorded, it is unlikely to have varied over more than a handful of years. The reason is to be found in Australian immigration regulations. With rare exceptions admission is not granted
B.K. Pierscionek Department of Physiology Faculty of Medicine Monash University Clayton

Victoria Australia

B.K. Pierscionek Department of Optometry University of Bradford Richmond Road Bradford West Yorks BD7 1DP, UK R.A. Weale Moorfields Eye Hospital London EC1V 2PD, UK

R.A. Weale Age Concern Institute of Gerontology King's College London London SE 1 8WA, UK

B.K.P. acknowledges generous assistance from Essilor International. R.A.W. thanks Research into Ageing for partial support 
to immigrants older than 50 years. Consequently it is reasonable to assume that those in their seventies have resided in Australia for more than 20 years, and this covers the vast bulk of our sample. Moreover, there was no detectable interval between the mean times of immigration of the two groups under consideration, namely Northern Europeans on the one hand and inhabitants of the Mediterranean and Adriatic regions on the other.

\section{Data analysis}

As the study is based on a comparison of prevalences for different types of cataract amongst different ethnic groups the analysis was based on the calculation of odds ratios. ${ }^{9}$ An odds ratio is defined as the ratio $c /(t-c)$, where $c$ is the number of cases with a given condition, and $(t-c)$ is the number without it. By comparing the odds ratios for two different sample populations one obtains a relative odds ratio (ROR). When the two odds ratios are equal then the relative odds ratio is equal to 1 . In this study interest centres on those RORs that differ from unity on a statistically significant level, and consequently offer a potentially useful tool in the analysis of inter-group variables.

When a large number of RORs is calculated it might happen that, say, 1 in 20 could be statistically significant simply due to chance. It is therefore possible to determine with what probability one would expect any one number of significant values. For example, 2 or 3 significant RORs amongst 40 would not be of any interest, but clearly 10-15 would require comment. Thus, the analysis is concerned only with those RORs that are significant with $p$ not more than 0.05 and, in addition, with a determination of the probability with which the number of RORs actually observed would be expected.

Table 1. Ethnic composition of North European and South European groups

\begin{tabular}{lc}
\hline Country & Number \\
\hline North European (NE) & 3 \\
Austria & 1 \\
Byelorussia & 2 \\
Czech Republic & 2 \\
Finland & 11 \\
Germany & 1 \\
Ireland & 1 \\
Latvia & 1 \\
Lithuania & 16 \\
Netherlands & 5 \\
Poland & 1 \\
Switzerland & 53 \\
United Kingdom & \\
South European (SE) & 18 \\
Cyprus & 84 \\
Greece & 21 \\
Italy & 35 \\
Malta & 2 \\
Turkey & \\
Former Yugoslavia & \\
\hline
\end{tabular}

It should be noted that only statistically significant RORs are presented and discussed. In the first instance, in order to assess the influence of age, the Australian group, which was the largest, was sub-divided into two age groups, namely those over and under 75 years, and called EAu and YAu respectively.

Secondly, to minimise the influence of age the data were again sorted according to gender and age. The NE data were the smallest in number (Table 1), and were, therefore, left intact. The genders were left separate at this stage to avoid any bias within each group. In order to compare NE with SE, who had the lower average age (Table 2a), the latter were curtailed in such a manner as to make the difference between the average ages of the two genders statistically non-different in the comparison groups. This meant that SE was trimmed to data for the older 55 women and 68 men. The comparison between the $\mathrm{Au}$ and the NE data required no adjustment. However, SE were, on average younger than $\mathrm{Au}$ (Table 2a). Accordingly, the older of the Au data were cut, leaving in this group 239 women and 105 men.

\section{Results}

The ethnic compositions of the NE and SE categories are shown in Table 1 . No statistically significant genderbased difference in the distribution of cataract types was found in any group: consequently the data for both genders were aggregated.

\section{Grouping by age}

Table 2a shows that the SE are on average younger than the NE and the Au ( $p<0.0001$ in both cases). The subdivision of the Australian data into $\mathrm{YAu}$ and $\mathrm{EAu}$ resulted in equal-sized groups, and a close age match between YAu and SE (Tables $2 a, b$ ). The relatively small amount of data made it impracticable to treat NE in the same way.

\section{Poisson probability assessment}

The $\mathrm{Au} / \mathrm{SE}$ and $\mathrm{Au} / \mathrm{NE}$ comparisons yielded 5 significant RORs out of a possible 14 (Table 3a, lines 1 and 2). Significance levels for each ROR are given in parentheses. A probability level of 0.05 would lead one to expect $0.7(=0.05 \times 14)$ ROR due to chance. Poisson sums show that, if, on average, 0.7 events are due to chance, then as many as 5 chance events would occur with a probability of 0.0007 .

When matched for age, the $\mathrm{Au} / \mathrm{SE}$ and $\mathrm{Au} / \mathrm{NE}$ comparisons yielded 7 significant RORs out of a possible 21 (Table $3 b$ ). A probability of 0.05 would lead one to expect $1.05(=0.05 \times 21)$ RORs due to chance. Poisson sums show that if, on average, 1.05 events are expected due to chance, then as many as 7 chance events would occur with a probability of 0.0001 . Note that the greater number of RORs is associated with nuclear or mixed nuclear cataracts.

The salient results are as follows: 


\begin{tabular}{|c|c|c|c|c|c|c|c|c|c|}
\hline & & & & Type & aract & & & & \\
\hline & $\mathrm{C}$ & $\mathrm{N}$ & $\mathrm{P}$ & $\mathrm{CN}$ & $\mathrm{NP}$ & PC & CNP & Total & Mean age (SD) \\
\hline (a) Aver & nposit & orincip & $c g^{r}$ & gende & catara & & & & \\
\hline $\mathrm{Au} \mathrm{F}$ & 102 & 80 & 30 & 87 & 40 & 45 & 23 & 407 & \\
\hline $\mathrm{Au} \mathrm{M}$ & 57 & 22 & 16 & 51 & 17 & 26 & 6 & 195 & \\
\hline $\mathrm{Au} \mathrm{T}$ & 59 & 102 & 46 & 138 & 57 & 71 & 29 & 602 & 77.79 (8.198) \\
\hline SE F & 37 & 4 & 4 & 37 & 3 & 6 & 8 & 99 & \\
\hline SE M & 33 & 4 & 11 & 11 & 2 & 8 & 5 & 74 & \\
\hline SE T & 70 & 8 & 15 & 48 & 5 & 14 & 13 & 173 & $69.39(8.565)$ \\
\hline NE F & 21 & 14 & 4 & 11 & 5 & 5 & 5 & 65 & \\
\hline NE M & 12 & 3 & 5 & 2 & 4 & 6 & 0 & 32 & \\
\hline NE T & 33 & 17 & 9 & 13 & 9 & 11 & 5 & 97 & $76.54(8.495)$ \\
\hline (b) $A v$ & posit & o as & wit & Aust & $a t a b y$ & act ty & & & \\
\hline $\mathrm{EAu}$ & 68 & 75 & 23 & 79 & 39 & 34 & 20 & 338 & $82.16(4.439)$ \\
\hline $\mathrm{YAu}$ & 91 & 27 & 23 & 59 & 18 & 37 & 9 & 264 & $70.01(5.942)$ \\
\hline
\end{tabular}

C, cortical; N, nuclear; P, posterior subcapsular; Au, native Australians (excluding Aborigines); SE, Southern Europeans; NE, Northern Europeans; $F$, female; $M$, male; $F+M=T$. $E$, $>75$ years; $Y<75$ years.

1. SE show a smaller ROR for nuclear cataract than do Au whether age-matched or not.

2. SE show a greater tendency for cataracts involving the cortical type than do $\mathrm{Au}$, and a smaller tendency for the nuclear type than either Au or NE.

3. Although the risk for nuclear cataract $(\mathrm{N})$ is known to increase with age, all the cataracts containing at least a cortical component $(C)$ show the opposite: the younger groups are at a greater risk from cortical and mixed cortical-nuclear and cortical-posteriorsubcapsular types $(\mathrm{C}, \mathrm{CN}, \mathrm{PC})$.

It is sometimes suggested that mixed cataracts are sums of their components, rather than conditions in their own right (cf. ${ }^{4}$ ) Accordingly RORs were also determined for C, N and P: i.e. these included the simple and the mixed types, which were naturally counted twice (or three times in the case of CNP). This manoeuvre led to the result that only $\mathrm{C}$ for $\mathrm{Au} / \mathrm{SE}$ was significant (1.36, $p=0.0235)$, although $\mathrm{P}$ for both $\mathrm{Au} / \mathrm{SE}$ and NE/SE was approaching significance. The amalgamation of the results led to a reversal of the ROR in the instance for $C$ mentioned (Table 3 ). It is to be noted that this procedure obscures the important point as to which of the two (or three) components came first and, therefore, involves an irretrievable loss of information. The above peculiar result may well be a consequence of this.

\section{Discussion}

The population used in this study was not a general but a clinical one, all subjects presenting with one of seven possible types of age-related cataract. However, because none of the population pairs shows 6 or 7 RORs divided into equal or almost equal numbers larger or smaller than 1 (e.g. 3 RORs $>1$ and 3 RORs < 1), no ROR, for any one type of cataract, is likely simply to be a consequence of RORs for other types. For example, RORs smaller than 1 for nuclear cataract in any of the groups compared with the SE are not complemented by a consistently higher relative risk in some other type(s) of cataract. It would seem to follow that none of the conclusions drawn from the data is attributable to the method of analysis.

The comparison Au/SE shows an ROR > 1 for nuclear (N) cataract (i.e. a greater relative risk of $\mathrm{N}$ for the $\mathrm{Au}$ group): this persists whether the pairs are age-matched or not, with only a decrease in the level of significance in

Table 3. Significant odds ratios (p-values in parentheses) for different types of cataract against sample population pairs

\begin{tabular}{|c|c|c|c|c|c|}
\hline & \multicolumn{5}{|c|}{ Type of cataract } \\
\hline & PC & $\mathrm{C}$ & $\mathrm{NP}$ & $\mathrm{CN}$ & $\mathrm{N}$ \\
\hline \multicolumn{6}{|c|}{ (a) Without regard to age differences } \\
\hline $1 \mathrm{Au} / \mathrm{SE}$ & & $0.528(0.00014)$ & & $3.514(0.008)$ & $4.208(0.00014)$ \\
\hline $2 \mathrm{NE} / \mathrm{SE}$ & & & $0.403(0.009)$ & $3.436(0.03)$ & \\
\hline $3 \mathrm{EAu} / \mathrm{SE}$ & & $0.371(0.009)$ & & $4.383(0.0053)$ & \\
\hline $4 \mathrm{EAu} / \mathrm{YAu}$ & $0.566(0.0232)$ & $0.514(0.00022)$ & & & $1.796(0.014)$ \\
\hline $5 \mathrm{YAu} / \mathrm{SE}$ & & & & & $2.35 \quad(0.044)$ \\
\hline $6 \mathrm{Au} / \mathrm{NE}$ & & & & $1.921(0.03)$ & \\
\hline \multicolumn{6}{|c|}{ (b) Matched for age } \\
\hline $1 \mathrm{Au} / \mathrm{SE}$ & $1.986(0.0038)$ & $0.688(0.0056)$ & & $0.637(0.041)$ & $3.272(0.0044)$ \\
\hline $2 \mathrm{NE} / \mathrm{SE}$ & & & & $0.333(0.0026)$ & $3.613(0.0094)$ \\
\hline $6 \mathrm{Au} / \mathrm{NE}$ & & & & $1.922(0.043)$ & \\
\hline
\end{tabular}

Column 1 identifies lines (see text). 
age-matched population pairs (line 5). The comparison $\mathrm{NE} / \mathrm{SE}$ also shows an ROR $>1$ for nuclear cataract. The latter has been associated with the inhalation of toxic fumes and with smoking. ${ }^{5-8}$ The quantification of substances that are inhaled or ingested is hard to determine from the usual questionnaires and, more importantly, the 'safety' threshold or tolerance levels, which would vary between individuals, are unknown.

Furthermore, there is no evidence to suggest that SE smoke less or were less exposed to airborne toxins than NE. If smoking is indeed a risk factor for nuclear cataract then the relative immunity of the Southern ethnic groups needs to be explained by one or more other factors. The relatively low prevalence of nuclear cataract amongst SE appears to be a real effect, unattributable to age.

It may be that the Mediterranean diet, rich in sources of alpha-linolenic acid which is thought to protect against coronary disease, ${ }^{10}$ plays a role in reducing the risk of nuclear cataract amongst SE as compared with $\mathrm{Au}$ and NE. Genetic predisposition has been reported only for age-related cortical cataract; ${ }^{3}$ we are not aware of any genetic basis for its nuclear counterpart, and offer dietary protection as a simpler and testable alternative hypothesis.

$\mathrm{Au}$ and NE differ only for a mixed cataract type (CN) in the comparison $\mathrm{Au} / \mathrm{NE}$ (Table 3). It should be noted that NE consisted of $55 \%$ of individuals born in the British Isles, while the ancestry of $\mathrm{Au}$ is also traced predominantly to the British Isles.
The authors thank all practitioners who contributed to the study.

\section{References}

1. Hodge WG, Whitcher JP, Satariano W. Risk factors for agerelated cataracts. Epidemiol Rev 1995;17:336-46.

2. West SK, Valmadrid CT. Epidemiology of risk factors for age-related cataract. Invest Ophthalmol Vis Sci 1995;37:1720-3.

3. Heiba IM, Elston RC, Klein BEK, Klein R. Evidence for a major gene for cortical cataract. Invest Ophthalmol Vis Sci 1995;36:227-35.

4. Weale RA. Inter-ethnic risk ratios for different types of cataract. Ophthalmic Res 1995;27:214-8.

5. Pierscionek BK, Weale RA. Odds ratios for different types of age-related cataract: ethnicity and environment. Ophthalmic Res 1996;28:88-92.

6. The Italian-American Cataract Study Group. Risk factors for age-related cortical, nuclear, and posterior subcapsular cataracts. Am J Epidemiol 1991;133:541-53.

7. Hirvela $\mathrm{H}$, Luukinen $\mathrm{H}$, Laatikainen L. Prevalence and risk factors of lens opacities in the elderly in Finland. Ophthalmology 1995;102:108-17.

8. Mohan M, Sperduto RD, Angra SK, Milron RC, Ravindera LM, Underwood BA, et al. and the India-US Case-Control Study Group. India-US case-control study of age-related cataracts. Arch Ophthalmol 1989;107:670-6.

9. Altman DG. Practical statistics for medical research. London: Chapman and Hall, 1996.

10. Salen P, Martin J-L, Monjaud I, Guidollet J, Touboul P, Delaye J. Mediterranean alpha-linolenic acid rich diet in secondary prevention of coronary heart disease. Lancet 1994;343:1454-60. 